Tropical Journal of Pharmaceutical Research January 2021; 20 (1): 169-175

ISSN: $1596-5996$ (print); 1596-9827 (electronic)

(C) Pharmacotherapy Group, Faculty of Pharmacy, University of Benin, Benin City, 300001 Nigeria.

Available online at http://www.tjpr.org

Original Research Article

http://dx.doi.org/10.4314/tjpr.v20i1.24

\title{
Assessment of awareness and satisfaction of online renewal of practising license among pharmacists in Nigeria
}

\author{
Ukamaka G Okafor ${ }^{1 *}$, Abubakar Ibrahim Jatau²,3, Olukemi Alabi ${ }^{4}$, Elijah NA \\ Mohammed $^{5}$ \\ ${ }^{1}$ Department of Education and Training, Pharmacists Council of Nigeria, Lagos, Nigeria, ${ }^{2}$ School of Pharmacy and \\ Pharmacology, University of Tasmania, Tasmania, Australia, ${ }^{3}$ Department of Pharmacy Practice, Pharmacists Council of \\ Nigeria, Head Office/Registry, ${ }^{4}$ Department of Inspection and Monitoring, Pharmacists Council of Nigeria, Head Office/Registry, \\ ${ }^{5}$ Registrar's Office, Pharmacists Council of Nigeria, Head Office/Registry, Abuja, Nigeria
}

*For correspondence: Email: chinaemelum9291@yahoo.com; Tel: +234-8033253463

Sent for review: 21 August 2020

Revised accepted: 14 December 2020

\begin{abstract}
Purpose: To assess the awareness and satisfaction of online renewal of practice licence among pharmacists in Nigeria.

Methods: This was a cross-sectional study among pharmacists in Nigeria. Participants were recruited through; online (via social media platforms) or in person at Pharmacists Council of Nigeria (PCN) office during application for renewal of license.

Results: A total of 878 participants completed the survey. Of this, 97.4 and $79.9 \%$ were aware and satisfied with the online process, respectively. The respondents rated the process as excellent (19.1\%), fair (22.2\%), good (55.0\%) and poor (3.6\%). Most of the reported challenges included linking payment of association dues with license renewal, poor customer service and password retrieval.

Conclusions: The level of awareness and satisfaction of the online renewal of annual licence among pharmacists in Nigeria is high. Measures are still needed to improve the online application process.
\end{abstract}

Keywords: Pharmacists Council, Online, Licence, Pharmacist, Practice

\begin{abstract}
This is an Open Access article that uses a fund-ing model which does not charge readers or their institutions for access and distributed under the terms of the Creative Commons Attribution License (http://creativecommons.org/licenses/by/4.0) and the Budapest Open Access Initiative (http://www.budapestopenaccessinitiative.org/read), which permit unrestricted use, distribution, and reproduction in any medium, provided the original work is properly credited.

Tropical Journal of Pharmaceutical Research is indexed by Science Citation Index (SciSearch), Scopus, International Pharmaceutical Abstract, Chemical Abstracts, Embase, Index Copernicus, EBSCO, African Index Medicus, JournalSeek, Journal Citation Reports/Science Edition, Directory of Open Access Journals (DOAJ), African Journal Online, Bioline International, Open-J-Gate and Pharmacy Abstracts
\end{abstract}

\section{INTRODUCTION}

Medicines are essentials and a critical part of healthcare services in all cultures and societies. When accessed, medicines are essential component for management and prevention of many diseases [1]. Thus, healthcare service may not be complete without safe, effective and affordable medicines [2]. Pharmacists were considered as the third most accessible healthcare professionals in the world and served as the first point of contact for many people in the community [3]. However, the continuous provision of healthcare services by a pharmacist is governed by a renewal of annual licence to practice by a regulatory body.

In Nigeria, the registration and issuance of annual licence to practice as a pharmacist is 
regulated by the Pharmacists Council of Nigeria, (PCN). This responsibility of registration and renewal of licence was supported by the National Drug Policy which recommends that "only duly licensed pharmacists shall have the authority to supply, sell and dispense drugs to the public [2].

Over the years, registration and annual renewal of licence for pharmacists and pharmaceutical premises in Nigeria were done manually, through the collection, filling and submission of forms to PCN nationwide offices, by the pharmacists [4]. Subsequently, the completed forms and evidence of payment are then forwarded to the PCN Head Office in the federal capital territory, for further processing and consequent registration or renewal of licence for such pharmacists or pharmaceutical premises [4].

With the increase in the use of Information Communication Technology (ICT) in the country, alongside the continuous innovations and improvement of regulatory activities, the PCN introduced the online renewal of annual licence for pharmacists and pharmaceutical premises in 2017 [4]. The process of online renewal of annual licences is widely used in many countries such as the United States and Great Britain $[5,6]$. To date, the two methods of annual renewal of licenses (manual and online) have been employed by the PCN. However, empirical data is lacking regarding the level of awareness and satisfaction of the online renewal of annual licence among the pharmacists in Nigeria. We, therefore, aimed to assess and provide this information, and to identify the common challenges faced by the pharmacists during the application processes and recommend guide for interventions to improve renewal of licence by pharmacists in Nigeria.

\section{METHODS}

\section{Study design/population}

The study was a cross-sectional design conducted among pharmacists in Nigeria. Nigeria has a population of about 196 million people with a growth rate of $2.6 \%$ annual change [7]. The country is divided into six geo-political zones; the North-West, North-East, North-Central, SouthWest, South-East and South-West. There were 14,878 pharmacists who renewed their annual license in 2019 [4]. These pharmacists practiced in various sectors; administration and regulation, hospital, community pharmacies, wholesale, pharmaceutical manufacturing, distribution, academia, research and development, consultancy and public health.
Participants are eligible in this study if they are registered and licensed pharmacists in Nigeria. Pharmacy graduates who were undergoing the National Youth Service Corp, and internship program were excluded in this study.

\section{Sample size determination}

The minimum number of participants was calculated using single proportion formula. There was no previous data regarding the proportion of pharmacists who were aware and satisfied with the online renewal of annual licence in Nigeria. We assumed the level of awareness and satisfaction among the sample to be $50 \%$. Assuming a precision of 0.05 at $95 \%$ confidence interval $(\mathrm{Cl})$, and z-value as 1.96 , we calculated a minimum sample size of the participants as 384. The survey remained active from January 29 to February 28, 2020.

\section{Development and validation of the questionnaire}

Being a novel study, a new questionnaire was developed from a review of literature and discussion with subject matter experts. The questionnaire was validated using face validity among the target participants and experts who are pharmacists with postgraduate degree and research experience. First, the questionnaire was presented to 10 experts for review. They were asked to give feedback in terms of relevance of the items to the study objective, wording and to identify those terms that may look ambiguous to the target participants. The questionnaire was revised based on the feedback received from these experts.

Secondly, the questionnaire was pretested among thirty pharmacists, recruited at PCN office, Lagos State during license application. The participants were requested to respond to the questionnaire and to identify any item/term that they misunderstood, ambiguous, or if there were other difficulties in responding to the scale. The results of this pretest were not provided in this study but the findings were used to update the questionnaire to the final version.

\section{Study procedure}

The validated questionnaire was used to assess the awareness and satisfaction of online renewal of an annual license among pharmacists in Nigeria. Two approaches were employed in the recruitment of participants to ensure increased participation of the pharmacists. A face-to-face and an online survey. For the face-to-face process, the paper-based questionnaire was self- 
administered to pharmacists as they were coming to the PCN office to renew their annual practice license. Participants signed an informed consent form before the survey. The online survey was conducted and reported based on the CHERRIES guidelines [8]. The final version of the questionnaire was designed into Google Form. The hyperlink to the Google Form was shared with the target participants through Facebook pages, Whatsapp groups and individual accounts (via the broadcast feature), Twitter handles and Linkedln profile of the authors. The hyperlink was also sent to the chairmen of the technical groups of the Pharmaceutical Society of Nigeria (PSN), for subsequent sharing to their group members. The primary outcome measures in this study are the level of awareness and satisfaction of online renewal of annual license.

\section{Statistical analysis}

Statistical analyses were conducted and reported based on statistical analyses and methods in the published literature (SAMPL) guidelines for basic statistical reporting [9]. Data cleaning, validation and statistical analyses were performed using the IBM SPSS statistics for windows, version 25.0. Armonk, NY: IBM corp. Data collected through the online survey were exported from the Google form (Excel format) to the SPSS, while those from the face-to-face interview were entered manually to the SPSS. Descriptive statistics were conducted to describe the socio-demographic characteristics of the participants, assessment of participants' awareness and satisfaction of the online registration. Categorical data were presented as frequency and percentages. Continuous variables were reported as mean and standard deviation depending on the normality distribution of the data. Chi-square or Fisher's exact test were used as appropriate to determine the differences in proportion among categorical variables.

\section{Ethical approval}

The study was administratively approved by PCN management. However, the study protocol was exempted from formal review and approval by the PCN research ethics committee as it did not involve the use of identifiable information of the respondents or institutions.

\section{RESULTS}

A total of 882 participants were recruited in the study; 103 and 779 participants responded to the paper-based and online survey, respectively. Of the 779 participants who responded to the online survey, four $(0.5 \%)$ started but did not complete the survey. Overall, a total of 878 complete responses $(99.5 \%$.) were included for analysis in the study.

\section{Sociodemographic characteristics of the study participants}

Table 1 demonstrates the sociodemographic characteristics of the study participants. The mean age (SD) of the participants was 42.5 (11.3). The youngest participant was 23 years old, while the oldest was 85 years old. Most of the respondents were in the age category of 31 to 40 years old $(31.8 \%)$, males $(57.5 \%)$, B. Pharm as the highest level of education (53.6\%), and practice in community pharmacies (47.4\%). The proportion of those with ten and below years of practice experience and from South-West geographical zone of the country were 40.3 and $61.6 \%$, respectively.

\section{Awareness of the online renewal of annual license among pharmacists in Nigeria}

Of the 878 participants, 855 (97.4\%) were aware of the online application for the renewal of annual license to practice as a pharmacist in Nigeria, while $23(2.6 \%)$ claimed they were not aware. Among those who were not aware of the online application process, none of them had ever applied for the renewal of annual license through the online methods. Most of these respondents were in the age category of $\leq 30$ years (35\%), from the South-West (65\%), with $\leq 10$ years of experience $(61 \%)$, and only $17 \%$ have ever applied for license using the manual methods. For those who were aware of the online renewal of the license, 785 (91.8\%) had applied through the process, while $70(8.3 \%)$ never did. Figure 1 indicates the pattern of the first application of license renewal using the online process. When participants were asked about how many times they ever applied for online renewal of the annual license, 5 (0.6\%) reported five times, 106 (12.1 $\%)$ four times, 280 (31.9\%) three times, 235 $(26.8 \%)$ twice, and $178(20.3 \%)$ only once.

\section{Satisfaction with the process of online renewal of the annual license}

Based on the Likert scale, 278 (31.7 \%) responded that they were very satisfied with the online application process, and 423 (48.2 \%) satisfied. While $129(14.7 \%)$ reported that they were not satisfied with the process, and 48 (5.5 $\%$ ) decided not to disclose their answer.

Trop J Pharm Res, January 2021; 20(1): 171 
Table 1: Sociodemographic characteristics of the participants $(n=878)$

\begin{tabular}{|c|c|c|c|c|}
\hline Variable & & $\begin{array}{l}\text { Median } \\
\text { (SD) }\end{array}$ & $\begin{array}{l}\text { Frequency } \\
(\%)\end{array}$ & $\begin{array}{c}\text { Registered } \\
\text { pharmacists in } \\
\text { Nigeria }^{1}, \mathrm{n}(\%)\end{array}$ \\
\hline Mean age (SD) & & $42.5(11.3)$ & & \\
\hline \multirow{4}{*}{ Age category } & 30 and below & & $155(17.7)$ & \\
\hline & 31 to 40 & & 279 (31.8) & \\
\hline & 41 to 50 & & $205(23.3)$ & \\
\hline & 51 and above & & $239(27.2)$ & \\
\hline \multirow[t]{2}{*}{ Gender } & Male & & 505 (57.5) & $8487(57.04 \%)$ \\
\hline & Female & & $373(42.5)$ & $6391(42.96 \%)$ \\
\hline \multirow[t]{5}{*}{ Level of education } & B. Pharm & & $471(53.6)$ & \\
\hline & PharmD & & $45(5.1)$ & \\
\hline & Masters/PGD & & $219(24.9)$ & \\
\hline & $\mathrm{PhD}$ & & $37(4.2)$ & \\
\hline & FPCPharm & & $106(12.1)$ & \\
\hline \multirow[t]{8}{*}{ Area of practice } & Academia & & $47(5.4)$ & \\
\hline & Administration/Regulation & & $81(9.2)$ & \\
\hline & Community & & $416(47.4)$ & \\
\hline & Hospital & & $202(23.0)$ & \\
\hline & Industry & & $64(7.3)$ & \\
\hline & Importation/Wholesale & & $27(3.1)$ & \\
\hline & Public Health & & $20(2.3)$ & \\
\hline & Others $^{2}$ & & $21(2.4)$ & \\
\hline \multirow[t]{4}{*}{$\begin{array}{l}\text { Year(s) of post- } \\
\text { graduation experience }\end{array}$} & 10 and below & & 354 (40.3) & \\
\hline & 11 to 20 & & $204(23.2)$ & \\
\hline & 21 to 30 & & $160(18.2)$ & \\
\hline & 30 and above & & 160 (18.2) & \\
\hline \multirow[t]{7}{*}{ Zone of practice } & North-West & & $79(9.0)$ & $1114(7.4)$ \\
\hline & North-East & & $41(4.7)$ & $601(4.0)$ \\
\hline & North-Central & & 99 (11.3) & $3190(21.6)$ \\
\hline & South-West & & $541(61.6)$ & $5955(40.0)$ \\
\hline & South-East & & $61(6.9)$ & $1596(10.7)$ \\
\hline & South-South & & $55(6.3)$ & 2307 (15.5) \\
\hline & Abroad & & $2(0.2)$ & $115(0.7)$ \\
\hline
\end{tabular}

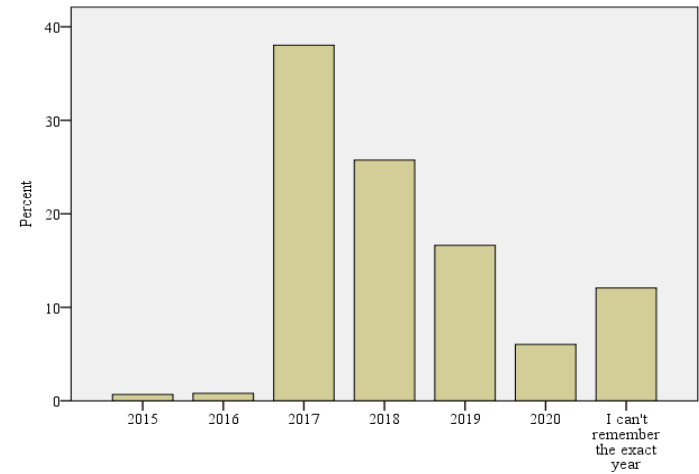

Figure 1: Pattern of first-time applicants for online renewal of annual license among the participants

Table 2 shows the level of satisfaction regarding the online renewal of annual license based on the sociodemographic characteristics of the participants. The proportion of participants who were very satisfied with the online process were those in aged 41 to 50 years (37.1\%), males $(37.6 \%)$, the undergraduate highest level of education (32.6 \%), practicing in the administration/regulation and participants with 21 to 30 years of practice experience. When respondents were asked to report about the methods they preferred, between the manual method (where pharmacists collect the application form at the PCN office, filled and returned) and the online application process, 718 $(81.8 \%)$ preferred the online methods, while 35 $(4.0 \%)$ selected manual method. Of the participants, $83(9.5 \%)$ said they were comfortable with any of the two methods.

\section{Satisfaction with the process of online renewal of the annual license}

Based on the Likert scale, 278 (31.7 \%) responded that they were very satisfied with the online application process, and 423 (48.2 \%) satisfied. While $129(14.7 \%)$ reported that they were not satisfied with the process, and 48 (5.5 $\%$ ) decided not to disclose their answer. 
Table 2: Satisfaction of online renewal of annual licence among pharmacists in Nigeria $(n=878)$

\begin{tabular}{|c|c|c|c|c|c|c|}
\hline \multirow[t]{2}{*}{ Variable } & & \multicolumn{4}{|c|}{ Satisfaction of online renewal of an annual licence } & \multirow[t]{2}{*}{$P$-value ${ }^{2}$} \\
\hline & & $\begin{array}{c}\text { Very } \\
\text { satisfied }\end{array}$ & Satisfied & $\begin{array}{c}\text { Not } \\
\text { satisfied }\end{array}$ & $\begin{array}{l}\text { Decided } \\
\text { not to } \\
\text { disclose }\end{array}$ & \\
\hline \multirow[t]{4}{*}{ Age category } & 30 and below & $38(24.5)$ & $74(47.7)$ & $29(18.7)$ & $14(9.0)$ & \multirow[t]{4}{*}{0.005} \\
\hline & 31 to 40 & $78(28.0)$ & $141(50.5)$ & $45(16.1)$ & $15(5.4)$ & \\
\hline & 41 to 50 & $76(37.1)$ & $86(42.0)$ & $35(17.1)$ & $8(3.9)$ & \\
\hline & 51 and above & $86(36.0)$ & $122(51.0)$ & $20(8.4)$ & $11(4.6)$ & \\
\hline \multirow[t]{2}{*}{ Gender } & Male & $190(37.6)$ & $238(47.1)$ & $51(10.1)$ & $26(5.1)$ & \multirow[t]{2}{*}{$<0.001$} \\
\hline & Female & $88(23.6)$ & $185(49.6)$ & $78(20.9)$ & $22(5.9)$ & \\
\hline \multirow[t]{2}{*}{ Education level } & BPharm & $168(32.6)$ & $242(46.9)$ & $70(13.6)$ & $36(7.0)$ & \multirow[t]{2}{*}{0.071} \\
\hline & Postgraduate & $110(30.4)$ & $181(50.0)$ & $59(16.3)$ & $12(3.3)$ & \\
\hline \multirow[t]{8}{*}{ Area of practice } & Academia & $18(38.3)$ & $18(38.3)$ & $10(21.3)$ & $1(2.1)$ & \multirow[t]{8}{*}{0.163} \\
\hline & Administration/Regulation & $35(43.2)$ & $35(43.2)$ & $8(9.9)$ & $3(3.7)$ & \\
\hline & Community & $142(34.1)$ & $193(46.4)$ & 58 (13.9) & $23(5.5)$ & \\
\hline & Hospital & $50(24.8)$ & $106(52.5)$ & $34(16.8)$ & $12(5.9)$ & \\
\hline & Industry & $18(28.1)$ & $33(51.6)$ & $10(15.6)$ & $3(4.7)$ & \\
\hline & Importation/Wholesale & $9(33.3)$ & $15(55.6)$ & $2(7.4)$ & $1(3.7)$ & \\
\hline & Public Health & $4(20.0)$ & $12(60.0)$ & $2(10.0)$ & $2(10.0)$ & \\
\hline & Others $^{1}$ & $2(9.5)$ & $11(52.4)$ & $5(23.8)$ & $3(14.3)$ & \\
\hline \multirow{5}{*}{$\begin{array}{l}\text { Year(s) of post- } \\
\text { graduation } \\
\text { experience }\end{array}$} & & & & & & \multirow[t]{5}{*}{$<0.001$} \\
\hline & 10 and below & $99(28.0)$ & $179(50.6)$ & $52(40.3)$ & $24(6.8)$ & \\
\hline & 11 to 20 & $57(27.9)$ & $90(44.1)$ & $47(36.4)$ & $10(4.9)$ & \\
\hline & 21 to 30 & $70(43.8)$ & $67(41.9)$ & $16(10.0)$ & $7(4.4)$ & \\
\hline & 30 and above & $52(32.5)$ & $87(54.4)$ & $14(8.8)$ & $7(4.4)$ & \\
\hline
\end{tabular}

${ }^{1}$ Non-governmental organizations/ insurance/consultancy; ${ }^{2}$ Chi-Square test

Table 3: Challenges encountered by the pharmacists during an online renewal of a license

\begin{tabular}{ll}
\hline Reported challenge & Frequency (\%) \\
\hline Difficulty in making online payments & $144(16.4)$ \\
Errors in printing licence & $108(12.4)$ \\
Inability to correct errors & $115(13.1)$ \\
Inability to retrieve a forgotten password & $237(27.0)$ \\
No response from PCN customer line & $431(49.1)$ \\
Linking payment of PSN dues with the online application & $218(24.8)$ \\
PCN online application website not explanatory enough & $101(11.5)$ \\
Not good at operating computer & $30(3.4)$ \\
\hline
\end{tabular}

Pharmacists' self-reported assessment of the online renewal of annual license

Of the total participants, $168(19.1 \%)$ rated the performance of $\mathrm{PCN}$ regarding the online application process as excellent, $195(22.2 \%)$ as fair, and 483 (55\%) as good. Twenty-four (2.7 $\%$ ) of the respondents described the process as poor, and $8(0.9)$ as very poor. When the participants were asked about the reasons for preferring the online process, the following explanations were given; very fast, easier, more convenient, ability to print out the license pending the issuance of the actual copy, accountability, simple, and more efficient compared to the manual methods.

Regarding the challenges encountered during the online process, the participants' experiences were summarized in Table 3.
Recommendations by participants on improving the online application process

1. Collection of a paper-based scratch card from PCN office has defeated the ideal "online" application process, therefore a secured electronic Personal Identification Number (ePIN) or a code should be introduced to replace the paper-based scratch card.

2. No step in the application process should entail physical visit to the PCN office.

3. The timeline for delivery of licenses should be shortened.

4. The payment of PSN dues should never be a prerequisite for the PCN application of annual license.

5. There should be a seemingly easier system for password retrieval.

Trop J Pharm Res, January 2021; 20(1): 173 
6. The online portal should have a mechanism to enable an applicant to correct an error or change a photograph.

7. There should be prompt feedback from the PCN customer line, or an officer should be dedicated to receiving complaints related to online applications.

8. The online portal needs overall improvements in terms of accessibility, navigation, efficiency, responsive and more user-friendly.

9. There is need to improve the awareness of PCN state officers and the other PCN pharmacists on the online processes.

\section{DISCUSSION}

This is the first study in the literature reporting the level of awareness, satisfaction and challenges of online renewal of annual license to practice as a pharmacist in Nigeria. The challenges experienced by the pharmacists with the new online application process despite the high level of awareness and satisfaction suggest the need for interventions and policy directions to improve the process.

This high level of awareness may be related to the widespread and persistent campaigns by the PCN through nationwide state offices, monthly newsletter "From the Registrar Desk", annual PSN conference, national dailies and during induction of new pharmacists to pharmacy profession. It is evident from this study that the few participants who lacked awareness about the PCN online renewal of licence had a younger age, with fewer years of professional practice experience. However, young pharmacists are expected to be more attracted with online registration than the older pharmacists. It is possible that these participants were not attentive during the induction programs while graduating from pharmacy schools. The induction program allows interaction between PCN and the new pharmacists joining the profession. It also provides the opportunity of updating the new pharmacists with registration and licensing process by the PCN. This finding calls for more research to investigate the reasons and the need for more strategies to address this awareness deficit among this category of pharmacists. There was no previous study on the subject matter for comparison. The possible reasons for the high level of satisfaction could be supported by other findings in the study. For instance, most of the participants who were satisfied with the online methods had longer years of post-graduation experience (implying longer years of using the manual methods Remita (https://www.remita.net/) is a unified financial system of online payment to the Federal Government of Nigeria. The problem of online payment identified in this study may be associated with the general challenges of Remita in Nigeria, such as poor network and system maintenance [10].

An important challenge reported by one-quarter of the participants is linking of payment for the license renewal with PSN dues. For the annual renewal of license in Nigeria, the law requires pharmacists to complete the mandatory continuing professional developments (MCPD) modules and payment of fees to the PCN [4]. This requirement is also applied in Kenya [11]. However, to increase compliance with PSN dues by pharmacists, the PCN now make payment PSN dues as a prerequisite to applying for license renewal [4]. This condition is what most of the respondents described as a requirement outside provision of the law and recommended separating the two (PSN dues and license application). This strategy is similar in Jordan, where to practice as a pharmacist, a person must register with the Jordan Pharmacists Association (JPA), pay appropriate dues, and licensed by the Ministry of Health [12]. Also, the annual renewal of registration with the JPA requires presentation of an annual licence [12]. However, in other countries such as Australia, the payment of association dues is not a prerequisite to renewal of pharmacist license [13]. The PCN may therefore need to review the process of using payment of PSN dues as a prerequisite for licence renewal in Nigeria.

While most of the pharmacists have expressed their satisfaction on the online application process, the reported technical shortcomings could be frustrating and discouraging. The PCN should therefore do a system maintenance and upgrade and dedicate a staff to respond to complaints related to application processes.

\section{Limitations of the study}

A majority of the participants were recruited via the online survey, thus, limiting inclusion of most of participants to those with internet access. However, to address this shortcoming, we utilized a face-to-face survey to recruit participants in PCN Lagos zonal office. Despite this, the proportion of our participants in terms of gender and geographical presentation is similar to the national data of registered pharmacists in Nigeria. 


\section{CONCLUSION}

The level of awareness and satisfaction of the online renewal of annual license among pharmacists in Nigeria is high. Measures are still needed to improve the online application process. The present study also provides a preliminary data that could guide interventions and policy directions towards improving online renewal of annual license in Nigeria. We recommend that the $\mathrm{PCN}$ should continuously improve the online application given the high level of satisfaction and excellent rating of performance. The challenges reported by the respondents should be addressed, while the recommendation suggested should be reviewed and implemented.

\section{DECLARATIONS}

\section{Acknowledgement}

The authors would like to thank and acknowledge the efforts of PCN staff, Chairmen of PSN and its technical groups for assisting in the data collection.

\section{Conflict of interest}

No conflict of interest is associated with this work

\section{Contribution of authors}

We declare that this work was conducted by the authors named in this article, and all liabilities relating to the content of this article were borne by authors. Ukamaka Gladys Okafor conceived the original idea, designed the questionnaire, developed the methods, was involved in the data collection and co-wrote the manuscript. Abubakar Ibrahim Jatau developed the methods, designed the Google Survey, involved in the data collection, conducted the statistical analysis and co-wrote the manuscript. Olukemi Alabi conducted the sample size analysis, designed the questionnaire and co-wrote the manuscript. Elijah Mohammed gave supervisory approval. All authors edited and critically reviewed the manuscript for intellectual content.

\section{Open Access}

This is an Open Access article that uses a funding model which does not charge readers or their institutions for access and distributed under the terms of the Creative Commons Attribution
License (http://creativecommons.org/licenses/by/ 4.0) and the Budapest Open Access Initiative (http://www.budapestopenaccessinitiative.org/rea d), which permit unrestricted use, distribution, and reproduction in any medium, provided the original work is properly credited.

\section{REFERENCES}

1. WHO. Joint FIP/WHO guidelines on good pharmacy practice: standards for quality of pharmacy services. [cited 2020 Jan 25]. Available from https://apps.who.int/medicinedocs/documents/s18676en /s18676en.pdf.

2. National Drug Policy, 2005. [cited 2020 Jun 8]. Available at http://collections.infocollections.org/whocountry/ en/d/js685e/.

3. Ekpenyong A, Udoh A, Kpokiri E, Bates I. An analysis of pharmacy workforce capacity in Nigeria. J Pharm Policy Pract 2018; 11(1): 20.

4. PCN. Pharmacists Council of Nigeria, 2020. [cited 2020 Jan 25]. Available from http://www.pcn.gov.ng/ index.php.

5. Pharmacists from the United States, 2020. [cited 2020 Feb 12]. Available on https://www.bcpharmacists.org/ pharmacist-us

6. General Pharmaceutical Council, 2020. [cited 2020 Feb 9]. Available from https://www.pharmacyregulation.org/ registration

7. National Bureau of Statistics. [cited 2020 Jun 8]. Available from https://www.nigerianstat.gov.ng/.

8. Eysenbach G. Improving the quality of Web surveys: The Checklist for Reporting Results of Internet E-Surveys (CHERRIES). J Med Internet Res 2004; 6(3).

9. Lang TA and Altman DG. Statistical analyses and methods in the published literature: The SAMPL guidelines. Guidelines for reporting health research: a user's manual (ed. David Moher, Douglas Altman, Kenneth Schulz, Iveta Simera and Elizabeth Wager) 2014; 264-274.

10. Kabiru S, Aliyu M. Electronic Payment System Challenges in Gombe State: Evidences from the Office of the Accountant General of Gombe State, Nigeria. Journal of Humanities and Social Science 2016; 21(4): 1-7.

11. Aywak D, Jaguga $C D$, Nkonge NG, Kinuthia R, Ambale C, Awle IA. Pharmacy Practice in Kenya. Can J Hosp Pharm 2017; 70(6): 456.

12. Nazer LH, Tuffaha $H$. Health care and pharmacy practice in Jordan. Can J Hosp Pharm, 2017; 70(2): 150.

13. Pharmacy Board. Renewal of pharmacist registration. Available from https://www.pharmacyboard.gov.au/ Codes-Guidelines/FAQ/Renewal.aspx. Access on 22/11/2020.,

Trop J Pharm Res, January 2021; 20(1): 175 